\title{
Teachers' Beliefs about Authoritative Teaching: Response and Demand, or Response and Control?
}

\author{
Bruce Torff \\ Correspondence: Bruce Torff, Hofstra University, USA. \\ Received: February 26, 2021 \\ Accepted: March10, $2021 \quad$ Online Published: March 11, 2021 \\ doi:10.11114/ijce.v4i1.5179 \\ URL: https://doi.org/10.11114/ijce.v4i1.5179
}

\begin{abstract}
In two studies, 254 secondary teachers completed a survey assessing beliefs about three putative factors of "authoritative teaching," response, demand, and control. Control was positively associated with response, suggesting that teachers viewed development of relationships with students as congruent with classroom discipline. But demand was not associated with response, suggesting beliefs holding that academic rigor does not necessarily undermine relationships. Teachers apparently view authoritative teaching as combining response and control, not response and demand. Beliefs as such provide a window on classroom practices and provide a starting point for teacher educators who aim to facilitate optimal interactional styles in schools.
\end{abstract}

Keywords: teachers' beliefs, authoritative teaching, interactional styles, responsiveness, demandingness, classroom management

\section{Introduction}

For over 50 years the factors underlying the interactions between caregivers and their charges have been a focus of interest in parenting (e.g., Baumrind, 1966, 1971), school psychology (e.g., Hetherington, 1993; Konold \& Cornell, 2015; Rutter et al., 1979), and teaching (e.g., Connor, Son, Hindman, \& Morrison, 2005; Perry, Donohue, \& Weinstein, 2007; Walker, 2008). A central tenet in this work is that interactional styles can be effectively modeled with a pair of factors, treated in educational theory and research as constituents of "authoritative teaching" (Maccoby \& Martin, 1983). The first of these encompasses the extent of teachers' efforts to enhance relationships with children by providing nurturance and emotional support; this factor might be called responsiveness, or simply response.

The second factor is not as readily defined. In some cases the second factor appears to involve academic requirements, such as giving rigorous assignments and ensuring accountability (e.g., Perry, Donohue, \& Weinstein, 2007); this factor might be called demand.

In other cases the second factor seems to entail disciplinary regulation, such as enforcement of classroom rules (e.g., Ertesvag, 2011); this factor could be described as control.

The two-factor model is prominent in a large body of theory and research in authoritative teaching, which asserts that optimal results are produced when teachers use an authoritative style that is high in both factors (e.g., Maccoby \& Martin, 1983). Less efficacious outcomes have been shown to result when teachers use an "authoritarian" style (low in response), a "permissive" style (low in demand and/or control), or a "disengaged" one (low in both factors). Authoritative teaching has been linked to positive outcomes with regard to students' academic performance, level of engagement, and sense of well-being in school, among other things (Connor, Son, Hindman, \& Morrison, 2005; Hetherington, 1993; Kiuru et al., 2012; Konold \& Cornell, 2015; Pellerin, 2005; Perry, Donohue, \& Weinstein, 2007; Rutter, 1979; Walker, 2008; Wentzel, 2002).

At the same time, lack of clarity concerning the makeup of the second factor leaves it unclear how authoritative teaching is structured. Moreover, recent research points to a degree of separation between demand and control, raising the possibility that authoritative teaching may involve three factors, not two (Connor, Son, Hindman, \& Morrison, 2005; Torff et al., 2020; Torff \& Kimmons, 2020). Research in this area has potential to determine which blend of factors is optimal for a variety of valued outcomes in schools, such as test scores, skills in important but hard-to-measure outcomes such as social skills, attitudes toward school, sense of belonging, and sense of well-being.

Accordingly, a central issue in this area involves teachers' beliefs concerning the factors of optimal teaching. With 
teachers' beliefs forming their understanding of how learning works and how teaching should proceed, their beliefs about interacting with students likely align fairly closely with their classroom practices in this regard (as discussed below). Do teachers see their work as optimized by a combination of response and demand? Or is it response and control? Or some amalgam of all three factors?

These questions were put to the test in two survey studies reported in this article. What follows includes a literature review, a problem statement for the research, the methods used, the results obtained, and a discussion of what the results indicate for theory, research, and practice in authoritative teaching.

\section{Literature Review}

Interactional styles in parenting. Baumrind (1966, 1971) initiated theory and research in interactional styles by categorizing parenting styles as permissive, authoritarian, and authoritative - terms now common across professions ranging from child care to business administration. In Baumrind's model, permissive parents believe in acting in an affirming and supportive manner, typically discussing policy decisions with children rather than dictating them (high response, low demand/control). Authoritarian parents, in contrast, believe in controlling children's behavior, often by imposing policy decisions from a position of authority that is not open to question (low response, high demand/control). Authoritative parents stake the middle ground, supervising children's activities but granting them a degree of autonomy, with policy decisions sometimes negotiated and sometimes dictated (high response, high demand/control). Maccoby \& Martin (1983) further developed this approach by framing two dimensions, responsiveness and demandingness, adding a "disengaged" or "indifferent" style low on both factors. This four-style scheme has become standard in classification of interactional styles in many professions, including education.

Interactional styles in school climate. The various interactional styles were assessed in research that endeavored to assess school climate - the general tenor of student-teacher interactions in a particular school (Hetherington, 1993). Results showed that students were higher in academic achievement and social competence in authoritative schools, relative to the other three school environments. Disengaged environments had the most negative impacts, particularly on students without authoritative parents. Similarly, Rutter et al. (1979) reported that schools produced more successful academic outcomes when teachers praised and encouraged student work (response) and emphasized the importance of academics (demand). In research conducted by Pellerin (2005), authoritative schools had the best overall outcomes, authoritarian schools had the highest dropout rates, and indifferent schools had the most disengaged students. Finally, Konold \& Cornell (2015) reported higher scores for student engagement and a lower incidence of peer aggression in schools where support from teachers (response) combined with a high level of academic structure (demand).

Interactional styles of individual teachers. Other research employs the four-style model to assess the beliefs and practices of individual teachers. Examining the effect of interactional styles on a variety of outcomes including student engagement, self-efficacy, and test results, Walker (2008) found that students in an authoritative teacher's class has higher academic self-efficacy and lower self-handicapping relative to students in an authoritarian teacher's class. Students with authoritative and authoritarian teachers produced similar test results, with both groups outscoring students with a permissive teacher. The researcher concluded that an authoritative teaching style produced optimal results in student learning and well-being.

Perry, Donohue, \& Weinstein (2007) reported that students had more favorable outcomes in classrooms wherein teachers provided social-emotional support (response) and emphasized instructional goals (demand). In these classrooms, students produced higher scores in math, generated fewer behavioral problems, and self-reported higher academic self-efficacy. Similar findings were reported by Kiuru et al. (2012).

Connor, Son, Hindman, \& Morrison (2005), using an assessment model similar to the one employed in the research reported below, measured three elements of teaching: warmth/responsivity, time spent on academic activities (demand), and classroom control. Teachers with higher sores for warmth/responsivity and classroom control produced higher student vocabulary scores. Teachers' scores for warmth/responsivity and classroom control were positively correlated, but neither variable was significantly correlated with time spent on academic activities. Although "time spent on academic activities" seems limited as an assessment of demand, the researchers' findings align with the ones reported in this article.

Further examining the notion that interactional styles may not be limited to two factors, Torff et al. (2020) evaluated the psychometric characteristics of a survey instrument design to assess three factors: response, demand, and control (described below). Results indicated that the three factors operated separately, indicating that all three may be involved in interactional styles. Evaluating the developmental path of teachers' beliefs about the three factors, Torff \& Kimmons (2020) reported that response scores diminished with age but increased with teaching experience. 


\section{Problem Statement}

The forgoing literature review provides evidence that authoritative teaching is associated with favorable outcomes in schools, when assessed as a school-wide factor or as a characteristic of individual teachers. But the literature remains unclear concerning the factors that make up authoritative teaching. There's substantial agreement that the first factor is response - teachers' efforts to provide a supportive and nurturing environment. But the consensus breaks down with additional factor(s), with some research appearing to focus on academic demand, and other studies honing in on classroom control, leaving it unclear how the second factor in authoritative teaching is constituted. And, complicating things further, evidence has emerged that demand and control may operate as separate factors, raising the possibility that three factors may be in play (Connor, Son, Hindman, \& Morrison, 2005; Torff et al., 2020; Torff \& Kimmons, 2020).

Also unclear is the role played by teachers' beliefs in theory and research in authoritative teaching. How teachers construe the basic elements of interacting with students goes a long way to determine the way they teach and what kind of outcomes they produce - in such outcomes as academic performance, engagement, and student well-being. Which combination of factors do teachers see as optimal in their classrooms? This question is addressed in two studies presented below.

\section{Study 1}

\section{Methods}

The research employed a single-group design in which a sample of teachers $(N=120)$ completed a survey that assessed beliefs about response, demand, and control. The survey in printed form was distributed to teachers at five secondary schools near a large city in the northeastern United States. Teachers completed the instrument at faculty meetings at their schools. Instructions indicated that the survey tapped opinions and had no correct answers, and all survey responses were confidential. Teachers were not compensated for participating.

The three dependent variables, response, demand, and control, were assessed with a survey used in prior research, the Teachers' Interactional Style Scale (TISS) (Torff et al., 2020). TISS measures each of the three factors with three items, yielding a total of nine items (see Table 1). Each item presents a statement with which respondents rate their strength of agreement. A response item, for example, is "Teachers who are responsive to students' needs get the most out of them." An example of a demand item is "Teachers can be effective without pressing students to work harder all the time" (note that this item utilizes reversed scoring; a high score shows a low level of demand, and vice versa). A sample control item reads, "The best classrooms have rules and routines clearly stated and consistently enforced." On the TISS instrument, respondents rate their strength of agreement with each item using 10-point scales (1=strongly disagree and $10=$ strongly agree). Each factor is constituted using the mean of the three items designed to assess that factor.

Table 1. Teachers' Interactional Style Scale

Response

Listening carefully to what students have to say fosters their learning

1. Teachers who are responsive to students' needs get the most out of them

2. Academic work improves when students sense the teacher cares about them

Demand

"Raising the bar" often fails to boost educational outcomes*

3. Teachers can be effective without pressing students to work harder all the time*

4. Students sometimes learn more when teachers avoid pushing too hard academically*

Control

Teachers who are clearly in charge get the most from students

5. A great many outstanding teachers favor no-nonsense classroom discipline

6. The best classrooms have rules and routines clearly stated and consistently enforced

Notes. * item worded for reverse scoring. All items scored on 10-point scales, from $1=$ strongly disagree to $10=$ strongly agree. For psychometric evaluation data see author identification deleted, 2020a. 
The psychometric properties of the TISS instrument were evaluated in a series of three studies (Torff et al., 2020). In the first study, exploratory factor analysis using the principal components method and varimax rotation was used to reduce 30 candidate items to nine, with three per factor $(N=255)$. A three-factor, nine-item model produced satisfactory factor-analytic results: $\mathrm{KMO}=.70$; explained variance $=62.6 \%$; eigenvalues of $2.60,1.75$, and 1.28 , with the next largest at .80; communalities $>.89$; and pattern/structure coefficients ("loadings") averaging .76 and ranging from .58 - .90. The three-factor, nine-item assessment model produced alpha values ranging from .54 to .84 and low or nonsignificant inter-factor correlations $(<.30)$. The three factors were interpreted as response, demand, and control, in accordance with the aims of assessment model. In Study 2 the same protocol was implemented using a separate sample $(N=150)$, with findings closely aligned with those of Study 1 . The third study showed that the scores of the TISS instrument correlated as expected with existing measures of response and control (Ertesvag, 2011), and both factors were weakly correlated with demand. In these studies, meaningful separation of demand and control was demonstrated, supporting the theoretical and practical utility of the three-factor approach to teachers' interactional styles used in the TISS instrument.

In addition to the three instructional-style factors, the survey assessed four demographic variables: age, educational attainment, gender, and teaching experience. Educational attainment was assessed in as highest degree earned (Bachelor's; Master's; Master's plus 30 credits; master's plus 60 credits; Doctorate). Gender was assessed as male, female, or other. Teaching experience was measured in years of full-time teaching completed.

\section{Results}

The dataset included 120 surveys assessing three interactional-style factors (response, demand, and control) and four demographic variables (age, educational attainment, gender, and teaching experience). SPSS version 25 was used in data analysis. Of the 1560 total cells (13 variables from 120 respondents), 38 (2.4\%) were missing, mainly from the variable age. No outliers were detected. Overall values for response, demand, and control were computed by taking the mean of the relevant items for each factor, bringing the dataset to a total of 16 variables.

Table 2. Study 1: Descriptive Statistics for Continuous Variables

\begin{tabular}{|c|c|c|c|c|c|}
\hline$\underline{\text { Variable } n}$ & Min & Max & Range & Mean & $S D$ \\
\hline Response 117 & 3.00 & 10.00 & 7.00 & 8.40 & 1.43 \\
\hline Demand 115 & 2.00 & 10.00 & 8.00 & 5.93 & 1.63 \\
\hline Control 120 & 1.67 & 10.00 & 8.33 & 7.50 & 1.48 \\
\hline Age & 23 & 66 & 43 & 38.55 & 10.34 \\
\hline Tch. Exp. 111 & 0 & 37 & 37 & 11.30 & 7.23 \\
\hline
\end{tabular}

Notes. Tch. Exp. $=$ teaching experience.

Participants taught in urban and suburban schools with students ranging in socioeconomic status, academic performance, and ethnicity. Academic subjects taught by these teachers included English, social studies, mathematics, sciences (biology, chemistry, Earth science, physics), and languages other than English. Table 2 and Table 3 present descriptive statistics for the sample. Participants had an average age of 38.16 years with 10.33 years of teaching experience. More than two-thirds were female, and $39.7 \%$ had completed a Master's degree as their highest degree earned. 
Table 3. Study 1: Descriptive Statistics for Categorical Variables

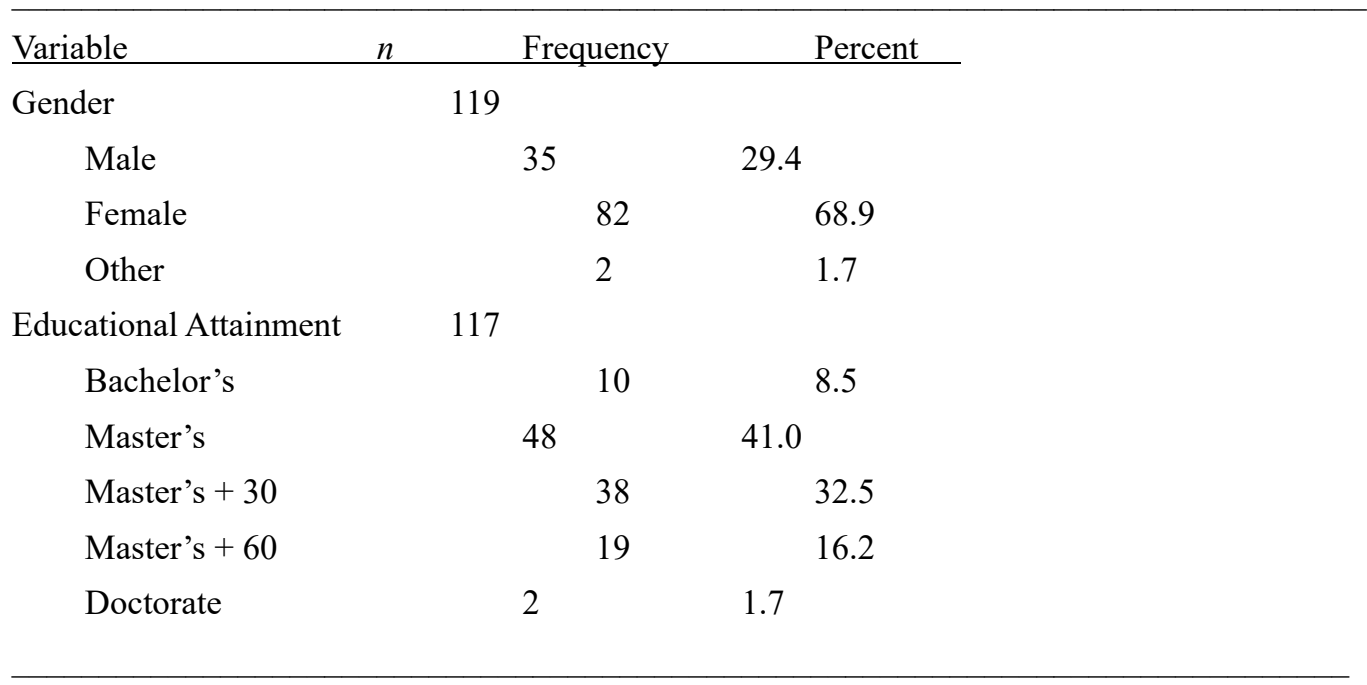

To evaluate the psychometric performance of the TISS instrument with the Study 1 sample, internal consistency reliability analysis was performed for each of its three factors (Table 1). Alpha levels obtained were .86 for response, .54 for demand, and .57 for control. These results are similar to those produced by TISS in other studies (Torff et al., 2020; Torff \& Kimmons, 2020).

A correlation matrix is presented in Table 4. Response scores were significantly correlated with control scores, but not demand scores, and demand and control were not significantly associated. These results suggest further analyses of the relationship of response to control. Response had a significant negative correlation with age (replicating results reported in Torff \& Kimmons, 2020). Otherwise the demographic variables were unrelated to response, demand, and control.

Table 4. Study 1: Correlation Matrix

\begin{tabular}{|c|c|c|c|c|c|c|c|c|c|}
\hline$\underline{1}$ & & 2 & & 3 & & 4 & 5 & 6 & \\
\hline 1. Response & & & ns & & $.20 *$ & & -.22 & ns & $\mathrm{ns}$ \\
\hline 2. Demand & ns & & & & ns & & ns & ns & ns \\
\hline 3. Control.20 & & ns & & & & ns & ns & ns & \\
\hline 4. Age & -.22 & & ns & & ns & & & $.34 * *$ & $.74 * *$ \\
\hline 5. Gender ns & & $\mathrm{ns}$ & & $\mathrm{ns}$ & & ns & & ns & \\
\hline 6. Ed. Att.ns & & ns & & ns & & $.34 * *$ & & ns & \\
\hline 7. Tch Exp. & ns & & $\mathrm{ns}$ & & ns & & $.74 * *$ & $\mathrm{~ns}$ & $.38 * *$ \\
\hline
\end{tabular}

Notes. * correlation significant at $p<.05 . * *$ correlation significant at $p<.01 . \mathrm{ns}=$ correlation not significant.

Tch. Exp. $=$ teaching experience. Ed. Att. = educational attainment.

A series of regression models were fit to examine the extent to which response was predicted by demand, control, and the four demographic variables. Response was entered as the dependent variable because research in this area shows that response is unambiguously a factor in authoritative teaching, but it remains unclear what effects are attributable to demand and control. Hence, it is useful to examine the extent to which response is predicted by demand and control (controlling for the four demographic variables). Assumptions testing was satisfactory with respect to linearity, multivariate normality (normality of residuals), homoscedasticity, and multicollinearity. Age and teaching experience might have been expected to produce multicollinearity, but they did not, with variance-inflation scores less than 2.42.

The initial model in the regression included response as the outcome variable and demand and control as predictors. Taken together, the predictors had a significant effect on the outcome $(f=3.2, p<.05)$. Demand was not a significant predictor of response, but control was, with a beta value of $.25(t=2.50, p<.05)$. 
A second model was fit entering the four demographic variables as additional predictors, to investigate the possibility that the results of the first model reflected artifacts of demographic characteristics. Only age significantly predicted response, with a beta value of $-.33(t=-2.16, p<.05)$; a one-year increment in age was associated with a third-of-a-point drop in response. Even when the effect of age was held constant, however, control remained a significant predictor of response $(t=2.80, p<.01)$, while demand had no significant effect. A one-unit increment in control was associated with a 28 increase in response. Including age in the model increased, slightly, the extent to which control contributed to the variance in response. These results suggest a meaningful association between response and control, but not between response and demand.

\section{Study 2}

\section{Methods}

A second study was conducted to replicate the findings of Study 1 with a different sample $(N=120)$. The methods used were identical in the two studies. As in the first study, participating teachers in Study 2 worked in urban and suburban schools near a large city in the northeastern United States, with students ranging in socioeconomic status, academic performance, and ethnicity. Academic subjects taught by teachers in Study 2 included English, mathematics, social studies, and science. No schools or teachers involved in the first study were included in the second one.

Table 5. Study 2: Descriptive Statistics for Continuous Variables

\begin{tabular}{|c|c|c|c|c|c|c|}
\hline Variable & $n$ & Min & $\operatorname{Max}$ & Range & Mean & $S D$ \\
\hline Response & 133 & 5.33 & 10.00 & 4.67 & 8.64 & 1.02 \\
\hline Demand & 132 & 1.00 & 10.00 & 9.00 & 5.69 & 1.68 \\
\hline Control & 133 & 2.33 & 10.00 & 7.67 & 7.29 & 1.38 \\
\hline Age & 118 & 23 & 67 & 44 & 42.33 & 9.94 \\
\hline Tch. Exp. & .124 & 1 & 41 & 40 & 16.08 & 8.70 \\
\hline
\end{tabular}

Notes. Tch. Exp. $=$ teaching experience.

As shown in Table 4 and Table 5, participants in Study 2 averaged 42.3 years of age and 16 years of teaching experience. More than $67 \%$ of participants were female, and $46 \%$ had completed a Master's degree plus 60 credits. The second sample was older, more experienced, and better educated than the first sample, although the gender distribution was similar.

Table 6. Study 2: Descriptive Statistics for Categorical Variables

\begin{tabular}{|c|c|c|c|}
\hline$\underline{\text { Variable }}$ & $n$ & Frequency & Percent \\
\hline Gender & & & \\
\hline Male & & 41 & 31.1 \\
\hline Female & & 90 & 68.2 \\
\hline Other & & 1 & .8 \\
\hline Educational Attainment & & & \\
\hline Bachelor's & & 2 & 1.5 \\
\hline Master's & & 43 & 32.1 \\
\hline Master's +30 & & 22 & 16.4 \\
\hline Master's +60 & & 62 & 46.3 \\
\hline Doctorate & & 5 & 3.7 \\
\hline
\end{tabular}

\section{Results}

Data analysis in Study 2 followed the protocol used in Study 1. The dataset included 134 surveys; of the 1742 cells, 42 (2.4\%) were missing, including 16 from age and 9 from teaching experience. No outliers were observed. Alpha 
levels in the second sample were .81 for response, .58 for demand, and .53 for control, indicating that the TISS instrument performed as expected with Study 2 data.

Table 6 presents a correlation matrix of these data. As in Study 1, response was significantly correlated with controlbut not with demand. Response was not significantly correlated with any of the four demographic variables, including age, which was correlated with response in the first sample. In contrast to results in the first study, a significant correlation was observed between demand and control, although the coefficient of .20 indicates a low degree of association. In general, in the second sample the demographic variables showed little relationship to response, demand, or control.

Table 7. Study 2: Correlation Matrix

\begin{tabular}{|c|c|c|c|c|c|c|c|c|c|c|}
\hline$\underline{1}$ & & 2 & & 3 & & 4 & 5 & & $\underline{6}$ & \\
\hline 1. Response & & & ns & & $.28 * *$ & & ns & & ns & ns \\
\hline 2. Demand & ns & & & & $.21 *$ & & ns & $\mathrm{ns}$ & & $\mathrm{ns}$ \\
\hline 3. Control .28* & & & $.21^{*}$ & & & & ns & $\mathrm{ns}$ & & $\mathrm{ns}$ \\
\hline 4. Age & ns & & ns & & $\mathrm{ns}$ & & & .ns & & $.28 * *$ \\
\hline 5. Gender ns & & ns & & ns & & ns & & & .ns & \\
\hline 6. Ed. Att.ns & & ns & & ns & & $.28^{* *}$ & & $\mathrm{~ns}$ & & \\
\hline 7. Tch. Exp. & ns & & $.20 *$ & & ns & & $.79^{* *}$ & & $\mathrm{~ns}$ & $.19^{*}$ \\
\hline
\end{tabular}

Notes. * correlation significant at $p<.05 . * *$ correlation significant at $p<.01 . \mathrm{ns}=$ correlation not significant.

Tch. Exp. $=$ teaching experience. Ed. Att. $=$ educational attainment.

Regression analysis was used to examine the effect of the predictors on response. Assumptions testing was satisfactory. Age and teaching experience produced VIF scores under 2.75. As in Study 1, the first model in the regression included response as the outcome variable and only demand and control as predictors. The combined predictors had a significant effect on the outcome $(f=4.26, p<.05)$. Demand did not contribute to the variance in response. Control did predict response, with a beta value of $.25(t=2.64, p<.01)$.

A second model was fit with the four demographic variables entered as additional predictors. Only teaching experience significantly predicted response, with a beta value of $.45(t=3.09, p<.01)$; a one-year increment in age was associated with almost half a point increase in response. However, even with the effect of teaching experience held constant, control remained a significant predictor of response $(t=2.97, p<.01)$, while demand had no significant effect. A one-unit increment in control was associated with a .28 increase in response. The inclusion of teaching experience in the model modestly increased the extent to which control contributed to the variance in response. Aligning with Study 1, these results suggest that as far as teachers are concerned, authoritative teaching unites response and control - not response and demand.

\section{Discussion}

Two survey-research projects were conducted to investigate teachers' beliefs about the factors associated with authoritative teaching. The first factor, response, has been consistently incorporated in theory and research in this area (at times called responsiveness or warmth/positivity). The second factor has been more challenging to pin down, with some sources focusing on academic requirements and others emphasizing classroom control, leaving it unclear how the second factor is constituted, or if three factors ought to be considered. Accordingly, the two studies reported in this article involve assessments of three factors, response, demand, and control, with the goal of examining how teachers weigh these factors in their beliefs about interacting with students.

The two studies suggest that teachers viewed the optimal interactional style as combining a high level of response with a high level of control, with neither factor strongly associated with demand. The findings comport with research conducted by Connor, Son, Hindman, \& Morrison (2005). A such, evidence is mounting that, as far as teachers are concerned, the optimal interactional style combines response and control, while demand is not as crucial an element in classroom interactions. A set of three implications follow from these findings.

\section{Specifying the Second Factor}

The results offer a new perspective for theory and research in interactional styles and authoritative teaching. As noted, 
this work has been ambiguous as to the nature of the second factor (demand or control) - in addition to first factor, response. Teachers' take on this matter, one argued in this paper to exert meaningful impact in schools, is that the optimal blend combines high response with high control. This is the value system embedded in modern schooling, at least for these two samples of teachers. Accordingly, research that treats the second factor as control is aligned with teachers' beliefs about classroom interactions. As such, response-and-control research has much to offer about interactions in schools - and about authoritative teaching (e.g., Baumrind, 1966, 1071; Connor, et al., 2005; Ertesvag, 2011; Kiuru, 2012; Konold \& Cornell, 2015; Maccoby \& Martin, 1983). In contrast, research that examines demand as the second factor does not align with how teachers prioritize their interactions with students, which may limit the utility of these findings (e.g., Perry, Donohue, \& Weinstein, 2007; Rutter et al., 1979).

The findings presented in this article underscore the influence of elements in child-rearing that are, in a sense, exported to educational settings. This brings the debate back to where it started, with Baumrind's work five decades ago (Baumrind, 1966, 1971). Seeking to characterize parenting styles, Baurmrind described three styles (authoritative, authoritarian, and permissive). Maccoby and Marin (1983) identified these styles as varying levels of two factors, with response and some combination of demand and control. These ideas have spread far and wide across the landscape not just in parenting, but also in such diverse fields as business administration and military personnel management. The original conception in the parenting literature, with response and control, appears to have the strongest empirical support, at least among the teachers involved in the studies reported here.

Perhaps this is not a coincidence. The two-factor model is at once simple and generative, helpfully describing such real-world phenomena as caregivers who are too hard-nosed, ones who are too accommodating, and ones who split the difference. The model captures the fundamentals of child rearing; on a daily basis, parents are confronted by the twin necessities of nurturing the child and supervising the child. There's love, but also the need to block fingers from sockets. In this sense, response and control are fundamental.

Demand is not, at least not in the same way. It is inherently academic, typically involving the imposition of a purposefully-structured curriculum, including assignments, tests, and other classroom vehicles uncommon in parenting situations. In child rearing, a "curriculum" (and thus a level of demand) is more loosely organized. Parents have explicit learning goals for children, of course; all want their progeny to learn to talk or eat. But the "curriculum" at home is remote from the developed, detail-specified curriculum seen in, say, $4^{\text {th }}$ grade math classes. Developed curriculum is the province of educators, whose job requires them to take on such tasks as organizing classroom activities and designing assessment vehicles. Parenting does so to a far lesser extent, and typically in a less organized manner.

So demand is the third factor that arrives on the scene, where response and control elements are already present. And it appears to carry less weight among teachers, perhaps because it is less deeply ingrained in our society's beliefs and norms about how learning works and teaching should proceed. In essence, response and control are fundamental to our society's construal of child rearing, while demand is an ancillary factor without the same primacy or urgency. Viewed as such, it is not surprising that teachers regard the optimal interactional style as combining response and control. These function as the left and right of working with children, students, or anyone else.

\section{Impact on Classroom Practices}

The case can be made that the beliefs reported in this article have much to say about how teachers actually carry out their interactions with students. Beliefs and behavior never align perfectly, of course (Fang, 1996). But what teachers believe plays out in what they do in their classrooms more often than not. Beliefs organize how teachers construe their occupation, forming their understandings of how learning works and how teaching should proceed (Richardson \& Placier, 2002; Torff, 2014). For example, if a teacher believes that learning is optimized when students are exposed to as much subject-matter content as possible, then lecture methods seem appropriate. Conversely, if a teacher believes that students quickly forget information they haven't thought about or worked with, then classroom activities that require students to think critically may seem in order. So the beliefs reported in this article likely provide a useful window on teachers' classroom practices.

Moreover, further indication that the beliefs assessed in this article portend of classroom practices is evident in the remote likelihood of false positives and false negatives that could undermine the validity of the results. It's possible some teachers value response but in the classroom are sometimes impatient - not a rare human foible. And it's possible that because nurturance for students is highly valued in many schools, some high scores for response could be more socially scripted than heartfelt. Accordingly, false positives concerning response probably occur in small numbers. However, false negatives, in which teachers say they don't value response but act responsively in the classroom, seem less likely. Perhaps the field includes some gruff teachers with big hearts - not unheard of, but likely not common. With response clearly identified as a constituent of authoritative teaching (e.g., Maccoby \& Martin, 
1983), it seems plausible that the data in this study indicate a penchant among teachers for a high level of responsiveness in their classroom interactions.

As for control, it's difficult to imagine that many teachers espouse a high level of classroom discipline and then act in a permissive manner in the classroom (a false positive). It follows that teachers long on classroom law and order act accordingly when students are present. And it seems improbable that a significant number of teachers downplay control in their beliefs but act like strict disciplinarians in class, so false negatives also are likely to be infrequent. Consequently, teachers' beliefs about control likely play out in their classroom behavior to a meaningful extent.

A similar argument holds for demand. Few teachers are inclined to espouse a great deal of academic rigor while asking relatively little from students. There's no apparent reason why teachers who see themselves as taskmasters would end up requiring a light load for students in the classroom. Conversely, teachers who espouse a low level of focus on academic rigor seem likely to behave accordingly in the classroom; it's not clear why would anyone say they don't judge it important to require a great deal from students and then, in the classroom, do exactly that. So neither false positives nor false negatives seem likely for demand. With data indicating that teachers do not see demand as occupying the same central role as response and control, it's probable that authoritative teachers are actually no more demanding in the classroom than are other teachers. As such, the data suggest that teaching and learning in the classrooms of authoritative teachers - not only the beliefs of these teachers - center on response and control.

These views were consistent across two samples of teachers, but other opinions will differ. Some commentators might prefer a greater emphasis on academic rigor, for example, while others might lament teachers' focus on control. The research here offers the issue for debate, and suggests where such a debate might well start: with the response-and-control beliefs favored by teachers.

\section{Implications for Teacher Education}

As a practical matter, the findings have potential to inform teacher education practices concerning the interactional-style factors valued in schools. With new teachers facing a need to adapt to the school environment, it may be helpful for teacher educators to demonstrate how educators typically place a premium on response and control, and to provide explicit classroom techniques for making a classroom responsive and well regulated. Techniques for response include, at minimum, listening skills, student choice, growth-mindset strategies, establishing a welcoming environment, offering praise liberally when warranted, and presenting reprimands non-judgmentally. Teacher-education practices centered on control include establishing clear rules and routines, watching the classroom carefully, using nonverbal strategies, redirecting students as needed, and implementing token economies (reward systems).

For educators who would prefer greater emphasis on demand, the climb is steeper. Demand is not an alien concept to teachers, but it is apparently not part of the fundamental belief system. Hence, teacher educators with an interest in demand are pressed to establish practices that encourage teachers to see the need for an academically challenging classroom. As such the endeavor is one of attempting to initiate belief change, which is often a tall order (Richardson \& Placier, 2002; Torff, 2014). Belief-change initiatives typically center on reflective thinking - using such classroom vehicles as journals, interviews, and close analysis of model of impoverish practice and best practice. Reflective thinking increases the likelihood of teacher buy-in, without which few initiates thrive. For teacher educators who wish to promote highly challenging pedagogy, prospective teachers' beliefs about demand draw the starting line.

\section{Limitations and Future Research}

The initial finding in this research was replicated in a second study, but additional replication with larger samples would add to confidence in the results. The research was conducted in a single geographical area and studies in other areas could produce different results. The samples in this research included secondary teachers, but elementary, special-education, or special-subject teachers may vary, as could teachers of different secondary subjects and special subjects (e.g., art, health). Future research also could examine how teachers' beliefs vary across various student populations, including general education students, special education students, and English language learners. Interactional-style beliefs also may differ according to student characteristics such as SES, gender, or ethnicity.

Finally, and perhaps most importantly, research is needed concerning the optimal blend of factors for a variety of valued outcomes, including test scores, but also skills in important but hard-to-measure outcomes such as social skills, attitudes toward school, sense of belonging, and sense of well-being. Teachers weigh in with their preferences in this article, and experts have reasoned opinions about which styles are optimal, but ultimately it seems important to determine how response, control, and demand predict academic performance and other valued outcomes in schools. 


\section{References}

Baumrind, D. (1966). Effects of authoritative parental control on child behavior. Child Development, 37, 887-907. https://doi.org/10.2307/1126611

Baumrind, D. (1971). Current patterns of parental authority. Developmental Psychology Monograph, 4(1, Part 2), 1-103. https://doi.org/10.1037/h0030372

Connor, C., Son, S., Hindman, A., \& Morrison, F. (2005). Teacher qualifications, classroom practices, family characteristics, and preschool experience: Complex effects on first graders' vocabulary and early reading outcomes. Journal of School Psychology, 43, 343-375. https://doi.org/10.1016/j.jsp.2005.06.001

Ertesvag, S. (2011). Measuring authoritative teaching. Teaching and Teacher Education, 27, 51-61. https://doi.org/10.1016/j.tate.2010.07.002

Fang, Z. (1996). A review of research on teacher beliefs and practices. Educational Research, 38 , $47-65$. https://doi.org/10.1080/0013188960380104

Hetherington, E. M. (1993). An overview of the Virginia longitudinal study of divorce and remarriage with a focus on early adolescence. Journal of Family Psychology, 7(1), 39-56. https://doi.org/10.1037/0893-3200.7.1.39

Kiuru, N., Aunola, K., Torppa, M., Lerkkanen, M., Poikkeus, A., Niemi, P., \& Nurmi, J. (2012). The role of parenting styles and teacher interactional styles in children's reading and spelling development. Journal of School Psychology, 50, 799-823. https://doi.org/10.1016/j.jsp.2012.07.001

Konold, T., \& Cornell, D. (2015). Measurement and structural relations of an authoritative school climate model: A multi-level latent variable investigation. Journal of School Psychology, 53, 447-461.

https://doi.org/10.1016/j.jsp.2015.09.001

Maccoby, E. E., \& Martin, J. A. (1983). Socialization in the context of the family: Parent-child interaction. In P. Mussen (Ed.), Handbook of Child Psychology Vol. 4. New York: Wiley.

Pellerin, L. A. (2005). Applying Baumrind's parenting typology to high schools: Toward a middle-range theory of authoritative socialization. Social Science Research, 34(2), 283-303. https://doi.org/10.1016/j.ssresearch.2004.02.003

Perry, K., Donohue, K., \& Weinstein, R. (2007). Teaching practices and the promotion of achievement and adjustment in first grade. Journal of School Psychology, 45, 269-291. https://doi.org/10.1016/j.jsp.2007.02.005

Richardson, V., \& Placier, P. (2002). Teacher change. In V. Richardson (Ed.), Handbook of Research on Teaching (4 ${ }^{\text {rd }}$ Ed., pp. 905-947). Washington, DC: American Educational Research Association.

Rutter, M., Maughan, B., Mortimore, P., \& Ouston, J. (1979). Fifteen thousand hours: Secondary schools and their effects on children. Cambridge, MA: Harvard University Press.

Torff, B., \& Kimmons, K. (2020). Learning to be a responsive, authoritative teacher: Effects of experience and age on teachers' interactional styles. The Educational Forum. https://doi.org/10.1080/00131725.2013.878424

Torff, B. (2014). Folk belief theory, the rigor gap, the achievement gap. The Educational Forum, 78, $174-189$. https://doi.org/10.1080/00131725.2013.878424

Torff, B., Kimmons, K., Bates, S., Benincasa, J., Budris, A., Casamassima, M., ... Walsh, M. (2020). Response, demand, and control: Evaluating a three-factor model and measure of teachers' interactional styles. The Educational Forum. https://doi.org/10.1080/00131725.2020.1702434

Walker, J. (2008). Looking at teacher practices through the lens of parenting style. The Journal of Experimental Education, 76(2), 218-240. https://doi.org/10.3200/JEXE.76.2.218-240

Wentzel, K. (2002). Are effective teachers like good parents? Teaching styles and student adjustment in early adolescence. Child Development, 73(1), 287-301. https://doi.org/10.1111/1467-8624.00406

\section{Copyrights}

Copyright for this article is retained by the author(s), with first publication rights granted to the journal.

This is an open-access article distributed under the terms and conditions of the Creative Commons Attribution license which permits unrestricted use, distribution, and reproduction in any medium, provided the original work is properly cited. 